\title{
Bone Mineral Density in Patients with Type 1 and Type 2 Diabetes Mellitus
}

\author{
Pınar Akpınar ${ }^{1}$, Afitap İçağasıoğlu ${ }^{2}$ \\ ${ }^{1}$ Department of Physical Medicine and Rehabilitation, University of Health Sciences Fatih Sultan Mehmet Training and Research \\ Hospital, Istanbul, Turkey \\ ${ }^{2}$ Department of Physical Medicine and Rehabilitation, Medeniyet University Goztepe Training and Research Hospital, Istanbul, Turkey
}

\begin{abstract}
Introduction: The aim of this study was to determine the effects of diabetes mellitus (DM) on bone mineral density (BMD) by comparing the BMD values of healthy controls with those of patients with type 1 and type 2 DM.

Methods: A total of 41 patients (23 men, 18 women) with type 1 DM aged 25 to 50 years and 40 (21 men, 19 women) sexand age-matched non-diabetic controls, as well as 91 patients (26 men, 65 women) with type 2 DM aged 40 to 55 years and 60 (17 men, 43 women) sex- and age-matched non-diabetic controls were included in the study. The BMD values of the fingers of the non-dominant hand were measured using an Alara Metriscan bone densitometer (Alara, Inc., Hayward, CA, USA). Patient height, weight, duration of DM, glycated hemoglobin ( $\mathrm{HbA} 1 \mathrm{C})$ value, and smoking and exercise history data were recorded. The level of statistical significance was established at $p<0.05$.

Results: The mean BMD value of the patients with type $1 \mathrm{DM}$ and the matched healthy controls was $58.29 \pm 5.42 \mathrm{~g} / \mathrm{cm}^{2}$ and $59.31 \pm 4.14 \mathrm{~g} / \mathrm{cm}^{2}$, respectively, while the mean BMD value in the type $2 \mathrm{DM}$ group and the matched healthy controls was $55.85 \pm 6.34 \mathrm{~g} / \mathrm{cm}^{2}$ and $55.93 \pm 7.40 \mathrm{~g} / \mathrm{cm}^{2}$, respectively. There was no statistically significant difference between the BMD value of either the type $1 \mathrm{DM}$ or the type $2 \mathrm{DM}$ group and the healthy controls. There was a significant negative correlation between the $\mathrm{HbA} 1 \mathrm{c}$ level and T-score and the BMD value in the type $1 \mathrm{DM}$ group, but no significant relationship was found in the type 2 DM group.

Discussion and Conclusion: There was no significant difference between the BMD value of the patients with either type 1 or type $2 \mathrm{DM}$ and the healthy controls.

Keywords: Bone mineral density; diabetes mellitus; osteoporosis.
\end{abstract}

$\mathrm{D}$ iabetes Mellitus (DM) is a chronic metabolic disease characterized by hyperglycemia, which can lead to mortality and morbidity, primarily due to micro- and macrovascular complications. Osteoporosis (OP) is a systemic bone disease characterized by deterioration in the bone architecture, a drop in bone mineral density (BMD), and an increase in bone fragility. Albright first mentioned a relationship between DM and OP in $19488^{[1]}$. Studies have reported a decrease in BMD in type $1 \mathrm{DM}$. However, a definitive understanding of the impact of type $2 \mathrm{DM}$ on $\mathrm{BMD}$

Correspondence (Illetişim): Pınar Akpınar, M.D. Department of Physical Medicine and Rehabilitation, University of Health Sciences Fatih Sultan Mehmet Training and Research Hospital, Istanbul, Turkey

Phone (Telefon): +90 21657830 00-34 39 E-mail (E-posta): pinar.pinarakpinar@gmail.com

Submitted Date (Başvuru Tarihi): 17.10.2017 Accepted Date(Kabul Tarihi): 18.11.2017

Copyright 2018 Haydarpaşa Numune Medical Journal

This is an open access article under the CC BY-NC-ND license (http://creativecommons.org/licenses/by-nc/4.0/). 
has not yet been determined. Nonetheless, recent meta-analyses have demonstrated a greater relative risk of fractures in type 1 and type 2 DM patients when compared with non-diabetics ${ }^{[2]}$.

A slight difference has been reported between DM-related $\mathrm{OP}$ and postmenopausal and senile $\mathrm{OP}{ }^{[3]}$. Bone turnover is achieved through a balance between metabolism and catabolism. A disruption of this balance affects bone quality and increases the risk of fracture. DM disrupts this turnover via various mechanisms. Bone turnover may be impaired as a result of insulin deficiency or resistance, hyperglycemia affecting the periphery of the bone and bone marrow, the accumulation of advanced glycation endproduct, a disrupted neuromuscular/skeletal system, or abnormal cytokine and adipokine production, which have harmful effects on bone cells ${ }^{[4]}$.

Insulin is an anabolic hormone, and its absence or excess affects bone metabolism in patients with DM. Insulin directly affects osteoblasts and osteoclasts. Furthermore, it decreases sex hormone-binding globulin, and increases the level of free estrogen and testosterone, leading to increased $\mathrm{BMD}{ }^{[3]}$. Though type 1 and type 2 DM are generally accepted as risk factors for the development of OP, its mechanism of action on BMD is unclear.

In our study, type 1 and type 2 DM patients aged 25 to 55 years and control groups were screened using radiographic absorptiometry (RA), then T-score, Z-score, and BMD values were compared to ascertain the effects of DM on BMD.

\section{Materials and Methods}

A total of 41 type 1 DM patients aged 25 to 50 years ( 23 men, 18 women), and 40 healthy, age-matched controls
(21 men, 19 women) were included in the study, as well as 91 patients aged 40 to 55 years with type 2 DM ( 26 men, 65 women) and 60 healthy, age-matched controls ( 17 men, 43 women). Patients with endocrinological or metabolic bone disease, malignancy, patients who used potentially osteoporotic drugs (steroids, antiepileptics, heparin), and postmenopausal women were excluded. Patients with a history of fracture or deformities involving the second, third, or fourth digits of their non-dominant hands were not included in the study. Patient's data regarding height, weight, duration of DM, HbA1c values, nutritional and menopausal status, and the smoking and exercise history of patients who agreed to participate in the study and who also gave their written, informed consent were recorded. The body mass index (BMI) of all participants was calculated.

The BMD value of the fingers of the non-dominant hand of all of the individuals in the study was measured using radiographic absorptiometry (RA) (Alara Metriscan bone densitometer; Alara, Inc., Hayward, CA, USA). BMD can be calculated from the second through the fourth fingers in a polyclinic setting in a very short time. The $\mathrm{X}$-ray radiation dose for each application is less than $0.012 \mu \mathrm{Sv}$, and it is a useful system for screening studies ${ }^{[5]}$. Ethics Committee approval was obtained from the ethics committee of Istanbul Göztepe Training and Research Hospital.

NCSS 2007 and PASS 2008 statistical software (NCSS, LLC, Kaysville, UT, USA) were used for the statistical analyses. Descriptive statistics of mean, SD, and frequency were used, and for the comparison of quantitative data, Student's t-test was used. The Mann-Whitney U test was applied to compare parameters with non-normal distribution. Spearman's correlation test was used for the analysis of

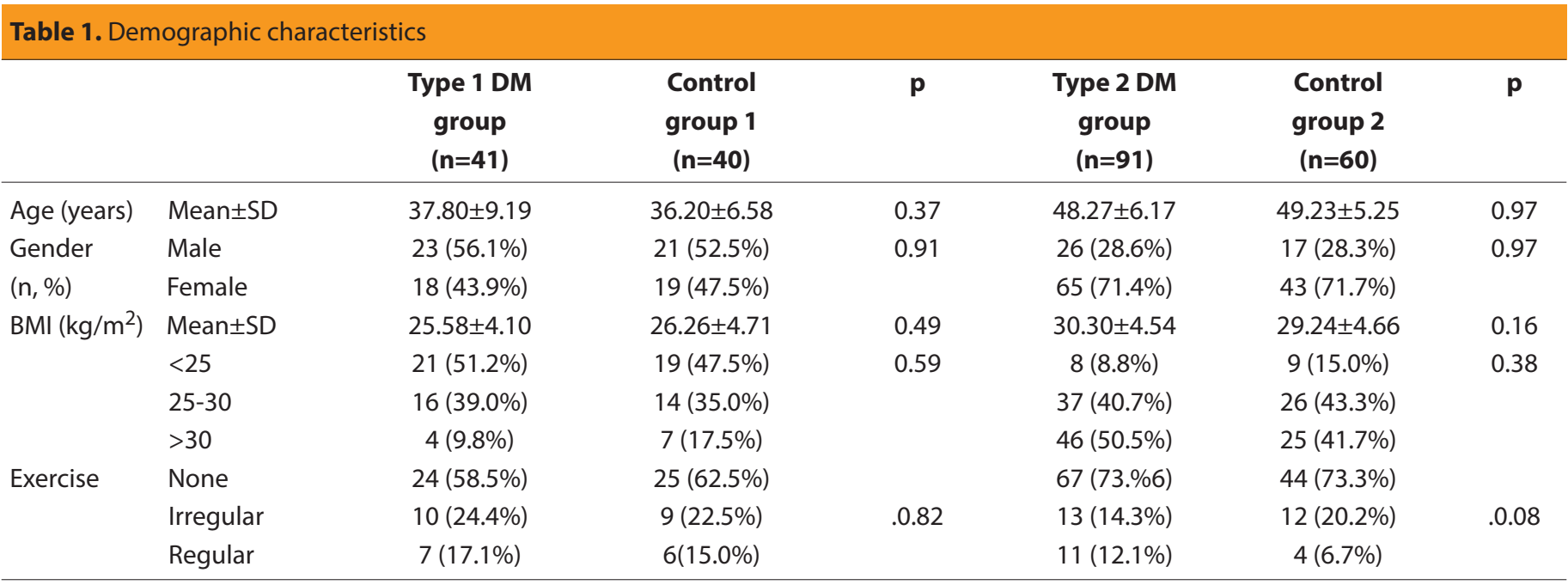

$p<0.05$. BMI: Body mass index; DM: Diabetes mellitus. 


\begin{tabular}{|c|c|c|c|c|}
\hline & \multicolumn{2}{|c|}{$\begin{array}{c}\text { Type } 1 \text { DM group } \\
(n=41)\end{array}$} & \multicolumn{2}{|c|}{$\begin{array}{l}\text { Type } 2 \text { DM group } \\
\qquad(\mathrm{n}=91)\end{array}$} \\
\hline & $\mathbf{n}$ & $\%$ & $\mathbf{n}$ & $\%$ \\
\hline \multicolumn{5}{|c|}{ HbA1c level } \\
\hline$<6.5$ & 6 & $15.0 \%$ & 21 & $32.1 \%$ \\
\hline$>6.5$ & 34 & $85.0 \%$ & 70 & $76.9 \%$ \\
\hline \multicolumn{5}{|c|}{ DM duration } \\
\hline$<10$ years & 20 & $48.8 \%$ & 71 & $78.0 \%$ \\
\hline$>10$ years & 21 & $51.2 \%$ & 20 & $22.0 \%$ \\
\hline
\end{tabular}

DM: Diabetes mellitus; HbA1c: Glycated hemoglobin.

Table 3. Comparison of T-score, Z-score, and BMD values in Type 1 DM and healthy control groups

\begin{tabular}{lccc}
\hline & $\begin{array}{c}\text { Type 1 DM group } \\
(\mathbf{n}=\mathbf{4 1}) \\
\text { Mean } \pm \text { SD } \\
\text { (median) }\end{array}$ & $\begin{array}{c}\text { Control group } \\
(\mathbf{n}=\mathbf{4 0})\end{array}$ & $\mathbf{p}$ \\
& $\begin{array}{c}\text { Mean } \pm \text { SD } \\
(\text { median})\end{array}$ & \\
\hline T-score hand & $0.40 \pm 1.28(0.37)$ & $0.58 \pm 1.00(0.69)$ & 0.587 \\
Z-score hand & $-0.029 \pm 0.96(-0.30)$ & $0.27 \pm 0.87(0.46)$ & 0.073 \\
BMD hand $\left(\mathrm{g} / \mathrm{cm}^{2}\right)$ & $58.29 \pm 5.42$ & $59.31 \pm 4.14$ & 0.348 \\
\hline
\end{tabular}

$\mathrm{p}<0.05$. BMD: Bone mineral density; BMI: Body mass index; DM: Diabetes mellitus.

correlations between parameters. The results were evaluated within a $95 \%$ confidence interval $(\mathrm{Cl})$ and $\mathrm{p}<0.05$ was selected as the level of statistical significance.

\section{Results}

The demographic features of the cases are demonstrated in Table 1. There was no statistically significant difference between type $1 \mathrm{DM}$ or type $2 \mathrm{DM}$ and the control groups in terms of age, gender, BMI, exercise, nutritional status (oral intake of caffeine, milk, and yogurt), smoking status, or presence of fractures $(p<0.05)$. As expected, the age and BMI of the type $2 \mathrm{DM}$ patients were higher than those of type 1 DM patients. Patients with type $2 \mathrm{DM}$ also exercised less compared with the type 1 DM patients $(p<0.05)$. The duration of disease and the $\mathrm{HbA} 1 \mathrm{c}$ level of the DM patients are shown in Table 2.

No statistically significant difference was detected between T-score, Z-score, or the BMD value of the patients with type $1 \mathrm{DM}$ and the matched healthy control group $(p<0.05)$ (Table 3). Similarly, a statistically significant difference was not detected between the T-score, Z-score, or the BMD value of the patients with type $2 \mathrm{DM}$ and the healthy controls $(p<0.05)$ (Table 4).
Table 4. Comparison of T-score, Z-score, and BMD values in Type 2 DM and healthy control groups

\begin{tabular}{lccc}
\hline & $\begin{array}{c}\text { Type 2 DM group } \\
(\mathbf{n}=\mathbf{9 1}) \\
\text { Mean } \pm \text { SD } \\
\text { (median) }\end{array}$ & $\begin{array}{c}\text { Control group } \\
(\mathbf{n = 6 0 )}\end{array}$ & p \\
& $\begin{array}{c}\text { Mean } \pm \text { SD } \\
\text { (median) }\end{array}$ & \\
\hline T-score hand & $-0.25 \pm 1.54(-0.02)$ & $0.23 \pm 1.76(-0.28)$ & 0.988 \\
Z-score hand & $0.06 \pm 1.08(0.08)$ & $-0.49 \pm 2.11(-0.22)$ & 0.200 \\
BMD hand $\left(\mathrm{g} / \mathrm{cm}^{2}\right)$ & $55.85 \pm 6.34$ & $55.93 \pm 7.40$ & 0.945
\end{tabular}

$\mathrm{p}<0.05$. BMD: Bone mineral density; BMl: Body mass index; DM: Diabetes mellitus.

A statistically significant negative correlation was detected when comparing the HbA1c, T-score, and BMD values in patients with type $1 \mathrm{DM}$, but a statistically significant correlation was not detected in these parameters in type $2 \mathrm{DM}$ patients. The BMD values of type $1 \mathrm{DM}$ patients with higher $\mathrm{HbA1c}$ values were statistically significantly lower than the $B M D$ values of type 1 DM patients with normal $\mathrm{HbA} 1 \mathrm{c}$ values $(p<0.05)$.

The duration of DM was not statistically significantly correlated with the T-score, Z-score, or BMD values in either the type 1 or type 2 DM group. Furthermore, nutritional status, exercise, and smoking habit did not statistically significantly correlate with the T-score, Z-score, or BMD values $(p<0.05)$.

\section{Discussion}

Although type 1 and type $2 \mathrm{DM}$, which affect the skeleton and bone metabolism, are recognized as potential risk factors for OP, the mechanism of action on BMD remains controversial ${ }^{[3,6]}$. In our study, we compared cases with type 1 and type $2 \mathrm{DM}$ with healthy controls, and no difference in the T-score, Z-score, or BMD value was found.

Literature studies performed with type $1 \mathrm{DM}$ patients have demonstrated a decrease in $B M D D^{[3,6,7,8]}$. Liu et al. (7) used a dual energy X-ray absorptiometer (DEXA) to measure femoral neck and vertebral BMD in type $1 \mathrm{DM}$ women aged 20 to 37 years and healthy, age-matched controls, and found lower BMD values in women with type $1 \mathrm{DM}$. They suggested the hypothesis that changes in BMD start at an early age in type $1 \mathrm{DM}$. Insulin deficiency is known to be a possible cause of impaired bone formation. In one study, when diabetic rats were given insulin therapy, abnormal bone turnover and BMD values normalized ${ }^{[9]}$. In another study of 62 patients with type $1 \mathrm{DM}$, after 7 years after intensive insulin therapy, normalization of all BMD values, a decrease in tartrate-resistance acid phosphatase, and 
an increase in parathormone secretion was detected ${ }^{[10]}$. In addition, improved metabolic control and nutritional status reportedly contributed to greater BMD values and maintenance of bone mass ${ }^{[11]}$. In our study, the finding of a negative correlation between $\mathrm{HbA} 1 \mathrm{c}$, T-score, and BMD values in type 1 patients emphasizes the importance of $\mathrm{gl}-$ ycemic control.

Strotmeyer et al. ${ }^{[12]}$ compared healthy women with female type $1 \mathrm{DM}$ patients in their premenopausal period, and determined that type $1 \mathrm{DM}$ women had a significantly lower $B M D$ value for femoral neck, total femur, and all body regions according to DEXA measurements and that calcaneal broadband ultrasound attenuation values assessed with quantitative ultrasound were lower than those of healthy controls ${ }^{[12]}$. However, in a similar study, no significant difference was detected between the DEXA BMD measurement of a control group and 38 (20 women and 18 men) patients (median age: 43 years) with a type 1 DM history of 33 years ${ }^{[13]}$. Similarly, in our study, the mean BMD value did not differ between either the type 1 or the type 2 DM patients and the control groups.

In meta-analyses, although normal or even high BMD values were measured for the hip and vertebra of type 2 patients, paradoxically, these patients have been reported to have an increased risk of fracture $[14,15,16]$. Vestergaard et al. ${ }^{[14]}$ compared type 2 DM patients with healthy controls and detected a 1.38 times greater relative risk (95\% Cl: $1.25-$ 1.53) of age-adjusted hip fracture in type $2 \mathrm{DM}$ patients. Schwartz et al. ${ }^{[17]}$ also demonstrated increased risk of bone fracture in type $2 \mathrm{DM}$, despite adjustments made for age, calcaneal BMD, BMI, and other covariants ${ }^{[17]}$.

The effects of glycemic control and diabetic complications on BMD are still debated. In a study performed with 38 male patients with type $2 \mathrm{DM}$, low BMD values were detected in cases with deficient glycemic control, impaired renal function, and long disease duration ${ }^{[18]}$. In another study of type 2DM patients with poor glycemic control it was reported that metabolic improvement decreased bone turnover in the short term, and as a result, good glycemic control might prevent bone loss in type 2 DM patients ${ }^{[19]}$. However, in some studies, authors have also reported the lack of any correlation between BMD and $\mathrm{HbA} 1 \mathrm{c}$ values ${ }^{[20]}$. In our study, too, no correlation was seen between $\mathrm{HbA1c}$ and BMD in patients with type $2 \mathrm{DM}$. It may be that we did not detect any correlation between $\mathrm{HbA} 1 \mathrm{c}$ and $\mathrm{BMD}$ in patients with type $2 \mathrm{DM}$ because our patients were younger than 55 years of age without any diabetic complications.

Now that the lifespan of diabetic patients is longer, the incidence of chronic complications has increased and the problem of diabetic osteopenia has become more important. The risk of fracture in type 2 DM patients has been thought to be related to environmental factors and decreased bone quality, rather than BMD. Though osteopenia is generally detected in patients with type $1 \mathrm{DM}$, it is not yet known with certainty whether osteopenia increases the risk of bone fracture. However, in order to decrease the risk of potential fracture, effective prophylaxis and treatment of diabetic osteopenia is the most important approach.

RA is highly correlated with DEXA, and the results are a significant indicator in the prediction of hip fracture ${ }^{[21]}$. It is an appropriate technique for an initial screening for osteoporosis, as it is easy to use, cost-effective, and the level of radiation exposure is relatively low ${ }^{[5]}$.

In our study, RA screening of patients with type 1 and type 2 DM did not reveal any evidence of osteopenia or any significant difference in BMD between the patient and control groups. The use of RA for screening and the small number of cases may be considered limitations of our study. Further studies with a larger number of cases are needed to evaluate diabetic complications and the risk of fracture, rather than BMD.

Ethics Committee Approval: The approval of the local Ethics Committee was obtained.

Peer-review: Externally peer-reviewed.

Authorship Contributions: Concept: P.A., A.I.; Design: P.A., A.I.; Data Collection or Processing: P.A.; Analysis or Interpretation: P.A., A.I.; Literature Search: P.A.; Writing: P.A.

Conflict of Interest: None declared.

Financial Disclosure: The authors declared that this study received no financial support.

\section{References}

1. Nathan DM. Long-term complications of diabetes mellitus. $\mathrm{N}$ Engl J Med 1993;328:1676-85. [CrossRef]

2. Yamamoto M. Insights into bone fragility in diabetes: the crucial role of bone quality on skeletal strength. Endocr J 2015;62:299-308. [CrossRef]

3. Merlotti D, Gennari L, Dotta F, Lauro D, Nuti R. Mechanisms of impaired bone strength in type 1 and 2 diabetes. Nutr Metab Cardiovasc Dis 2010;20:683-90. [CrossRef]

4. Hofbauer LC, Brueck CC, Singh SK, Dobnig H. Osteoporosis in patients with diabetes mellitus. J Bone Miner Res 2007;22:1317-28. [CrossRef]

5. Boonen S, Nijs J, Borghs $H$, Peeters $H$, Vanderschueren D, Luyten FP. Identifying postmenopausal women with osteoporosis by calcaneal ultrasound, metacarpal digital $\mathrm{X}$-ray radiogrammetry and phalangeal radiographic absorptiometry: a com- 
parative study. Osteoporos Int 2005;16:93-100. [CrossRef]

6. Tell-Lebanon O, Rotman-Pikielny P. Osteoporosis And Diabetes - In Which Way Are They Related? Harefuah 2016;155:697-701.

7. Liu EY, Wactawski-Wende J, Donahue RP, Dmochowski J, Hovey KM, Quattrin T. Does low bone mineral density start in post-teenage years in women with type 1 diabetes? Diabetes Care 2003;26:2365-9. [CrossRef]

8. Nicodemus KK, Folsom AR; lowa Women's Health Study. Type 1 and type 2 diabetes and incident hip fractures in postmenopausal women. Diabetes Care 2001;24:1192-7. [CrossRef]

9. Mishima N, Sahara N, Shirakawa M, Ozawa H. Effect of streptozotocin-induced diabetes mellitus on alveolar bone deposition in the rat. Arch Oral Biol 2002;47:843-9. [CrossRef]

10. Campos Pastor MM, López-Ibarra PJ, Escobar-Jiménez F, Serrano Pardo MD, García-Cervigón AG. Intensive insulin therapy and bone mineral density in type 1 diabetes mellitus: a prospective study. Osteoporos Int 2000;11:455-9. [CrossRef]

11. Bonfanti R, Mora S, Prinster C, Bognetti E, Meschi F, Puzzovio $M$, et al. Bone modeling indexes at onset and during the first year of follow-Up in insulin-dependent diabetic children. Calcif Tissue Int 1997;60:397-400. [CrossRef]

12. Strotmeyer ES, Cauley JA, Orchard TJ, Steenkiste AR, Dorman JS. Middle-aged premenopausal women with type 1 diabetes have lower bone mineral density and calcaneal quantitative ultrasound than nondiabetic women. Diabetes Care 2006;29:306-11. [CrossRef]

13. Ingberg CM, Palmér M, Aman J, Arvidsson B, Schvarcz E, Berne
C. Body composition and bone mineral density in long-standing type 1 diabetes. J Intern Med 2004;255:392-8. [CrossRef]

14. Vestergaard P. Discrepancies in bone mineral density and fracture risk in patients with type 1 and type 2 diabetes- a meta-analysis. Osteoporos Int 2007;18:427-44. [CrossRef]

15. Schacter GI, Leslie WD. Diabetes and Bone Disease. Endocrinol Metab Clin North Am 2017;46:63-85. [CrossRef]

16. Janghorbani M, Van Dam RM, Willett WC, Hu FB. Systematic review of type 1 and type 2 diabetes mellitus and risk of fracture. Am J Epidemiol 2007;166:495-505. [CrossRef]

17. Schwartz AV1, Sellmeyer DE, Ensrud KE, Cauley JA, Tabor HK, Schreiner PJ,et al; Study of Osteoporotic Features Research Group. Older women with diabetes have an increased risk of fracture: a prospective study. J Clin Endocrinol Metab 2001;86:32-8. [CrossRef]

18. Kao CH, Tsou CT, Chen CC, Wang SJ. Bone mineral density in patients with noninsulin-dependent diabetes mellitus by dual photon absorptiometry. Nucl Med Commun 1993;14:373-7.

19. Okazaki R, Totsuka Y, Hamano K, Ajima M, Miura M, Hirota Y, et al. Metabolic improvement of poorly controlled noninsulin-dependent diabetes mellitus decreases bone turnover. J Clin Endocrinol Metab 1997;82:2915-20. [CrossRef]

20. Bartos V, Jirkovská A, Kasalický P, Smahelová A, Vondra K, Skibová J. Osteopenia and osteoporosis in diabetic women over 40 years of age. Cas Lek Cesk 2001;140:299-301.

21. Adams JE. Radiogrammetry and radiographic absorptiometry. Radiol Clin North Am 2010;48:531-40. [CrossRef] 